\title{
TL AND OSL DATING OF SEDIMENT AND POTTERY FROM TWO SYRIAN ARCHAEOLOGICAL SITES
}

\author{
JORGE SANJURJO SÁNCHEZ ${ }^{1}$, DANIEL FERNÁNDEZ MOSQUERA ${ }^{1}$ \\ and JUAN LUÍS MONTERO FENOLLÓS ${ }^{2}$ \\ ${ }^{1}$ Instituto Universitario de Xeoloxía, Universidade da Coruña, \\ Campus de Elviña s/n, 15071 A Coruña, Spain \\ ${ }^{2}$ Departamento de Humanidades, Facultade de Humanidades, Universidade da Coruña, \\ c/ Dr Vázquez Cabrera s/n, 15403 Ferrol, A Coruña, Spain
}

\begin{abstract}
Luminescence dating is widely applied nowadays, mainly for archaeological material and artefacts and sediments of all types and origins. However, optically stimulated luminescence (OSL) from archaeological sediment, originated from mud brick buildings has been hardly studied. The archaeological sites of Tall Abu Fahd and Tall Qsubi are located in the Middle Euphrates Valley, Deir ez-Zor district, Syria. These two Bronze Age sites were recently discovered by a Spanish-Syrian team from the Directorate General of Antiquities and Museums (Damascus) and the University of Coruña. Both sites were dated (about $3.5 \mathrm{ka} \mathrm{BC}$ ) by typological pottery classification. Sediment and pottery samples from these archaeological sites were collected for luminescence dating. Several analytical procedures for obtaining equivalent doses were tested on the sediment samples. Blue OSL from quartz subsamples and IRSL, post IRSL Blue OSL from feldspar contaminated quartz and polymineral subsamples were performed to obtain OSL ages. For the pottery samples, additive dose TL on a coarse grain feldspar contaminated quartz subsample was performed as well. Results have shown agreement among all the luminescence procedures tested on the Tall Abu Fahd site samples after fading correction, showing ages around $2.7 \mathrm{ka}$ BP. Obtained ages from the other site samples show disagreement among quartz blue OSL and the other subsamples. Fading ratios allow correcting age underestimations from the polymineral post-IR OSL signal. However, the polymineral IRSL signal still shows underestimation. Final sediment and pottery ages have shown good agreement. Older ${ }^{14} \mathrm{C}$ independent age (3.32 ka BP) corresponds to occupational periods of the site while sediment ages are attributed to a post occupation phase.
\end{abstract}

Keywords: OSL, TL, Syria, Bronze Age.

\section{INTRODUCTION}

Among dating methods, luminescence dating has been widely applied to both archaeological materials and geologic sediments in the last decades. At present, this is an extended dating method in archaeology. In this way, thermoluminescence (TL) dating is used to date fired materials such as pottery, flint and others, and it determines the time elapsed since the mineral grains have been heated. The additive dose protocol (Aitken, 1985) is the most useful technique to obtain reliable equivalent doses

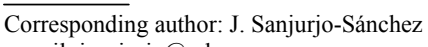
e-mail: jsanjurjo@udc.es

ISSN 1897-1695 (online), 1733-8387 (print) (C) 2008 GADAM Centre, Institute of Physics, Silesian University of Technology.

All rights reserved.
$\left(D_{e}\right)$ for fired materials. Optically stimulated luminescence (OSL) dating is applied to obtain sediment sample ages, and it determines the time elapsed since mineral grains have been last exposed to light just before burial. The Single Aliquot Regenerative dose (SAR) protocol (Murray and Wintle, 2000) was introduced as a method of obtaining a reliable value for an unknown dose received by quartz grains.

While OSL dating shows a variety of applications for sediment material, there is a shortage regarding sediment dating of archaeological origin. These sediments were early studied by Grogler et al. (1958). However, sediments from the Euphrates Valley in the Near East have not been studied up to now by quartz or polymineral fine grain dating. The origin of this sediment is the decompo- 
sition of mud bricks, usually employed to build towns in the Euphrates Valley and Near East Bronze Age Period. In this part of the world, most archaeological sites were inhabited during several periods of the Bronze Age and historic times by different cultures. In these sites, clayish sediments from the decomposition of mud bricks settled to form the different sediment layers. Thus, many other materials like bones, pottery fragments and charcoals have been found on them, revealing human activity in every site. However, problems such as bricks or clay reutilization, re-excavation of sediment in the different occupation phases, or floods from the Euphrates River, could complicate the collection and analysis of the samples and the interpretation of stratigraphic profiles and the final results in order to obtain reliable luminescence ages. Thus, to avoid these problems, sampling was restricted to one layer in the studied profiles.

The aim of this work is to obtain reliable OSL ages from quartz and polymineral subsamples extracted from archaeological sediments from two sites of the Euphrates Valley (Syria). Results obtained by sediment OSL and pottery TL have been compared with an independent ${ }^{14} \mathrm{C}$ control age.

\section{Archaeological sites}

The Middle Syrian Euphrates Valley in the Deir ezZor district has been object of different archaeological surveys from the 60's to the present. Data reported from these studies have shown that this sector (between basaltic gorge of Halabiya and Deir ez-zor) is not very wellknown from the archaeological point of view. The Euphrates axis was an important communication way in the pre-classical Antiquity, when the river was navigable along the main part of its course. In the Middle Euphrates, the Khabur and Balikh are the other communication axes of that region. Both rivers functioned as a way between the Euphrates Valley and Anatolia (Montero Fenollós et al., 2006b).
In the last two years, one Syro-Spanish team of the Directorate General of Antiquities and Museums (Damascus, Syria) and the Faculty of Humanities of the University of Coruña (A Coruña, Spain) have started a collaboration agreement to investigate the archaeological sites of the district of Deir ez-Zor. The aim of the study is to extend the knowledge about the cultural and politic evolution of this area over the Syro-Mesopotamian Kingdom of Mari (2900-1760 BC), i.e., in the Early and Middle Bronze Ages.

In the first two years of work (2005-2006), more than five sites were investigated (Montero Fenollós et al., 2006a and 2006b). The archaeological sites of Tall Abu Fahd and Tall Qsubi (Fig. 1) were chosen to collect sediment and pottery samples to date them by luminescence. These two sites were dated from Middle Bronze and Early Bronze, respectively, by means of distinctive pottery classification from samples collected in both sites.

Tall Abu Fahd (TAF) is located at the end of the Halabiya/Hanuqa gorge on the left side of the Euphrates River, next to the Abu Fahd Village. There is a wall of basaltic ashlars on the bound and a tower of rectangular floor $(10 \times 10 \mathrm{~m})$ in the North Eastern corner. At the west and south sides, there is a hole where the stratigraphic sequence could be studied. In agreement with Lauffray (1983) the site was occupied in the Roman and Islamic periods. However, pottery fragments correspond to Middle Bronze Age II (1800-1650 BC).

Tall Qsubi (TQ) is located at the entrance of the Hanuqa gorge on the right side of the Euphrates River, next to the Qsubi village. There is a little acropolis and a downtown. On the east boundary, the people of the village have built a hole where the site profile can be seen. Pottery fragments collected on surface come from Bronze Age and the Islamic Period. The stratigraphic sequence shows occupation in the Early Bronze Age IV (2300$2000 \mathrm{BC})$.

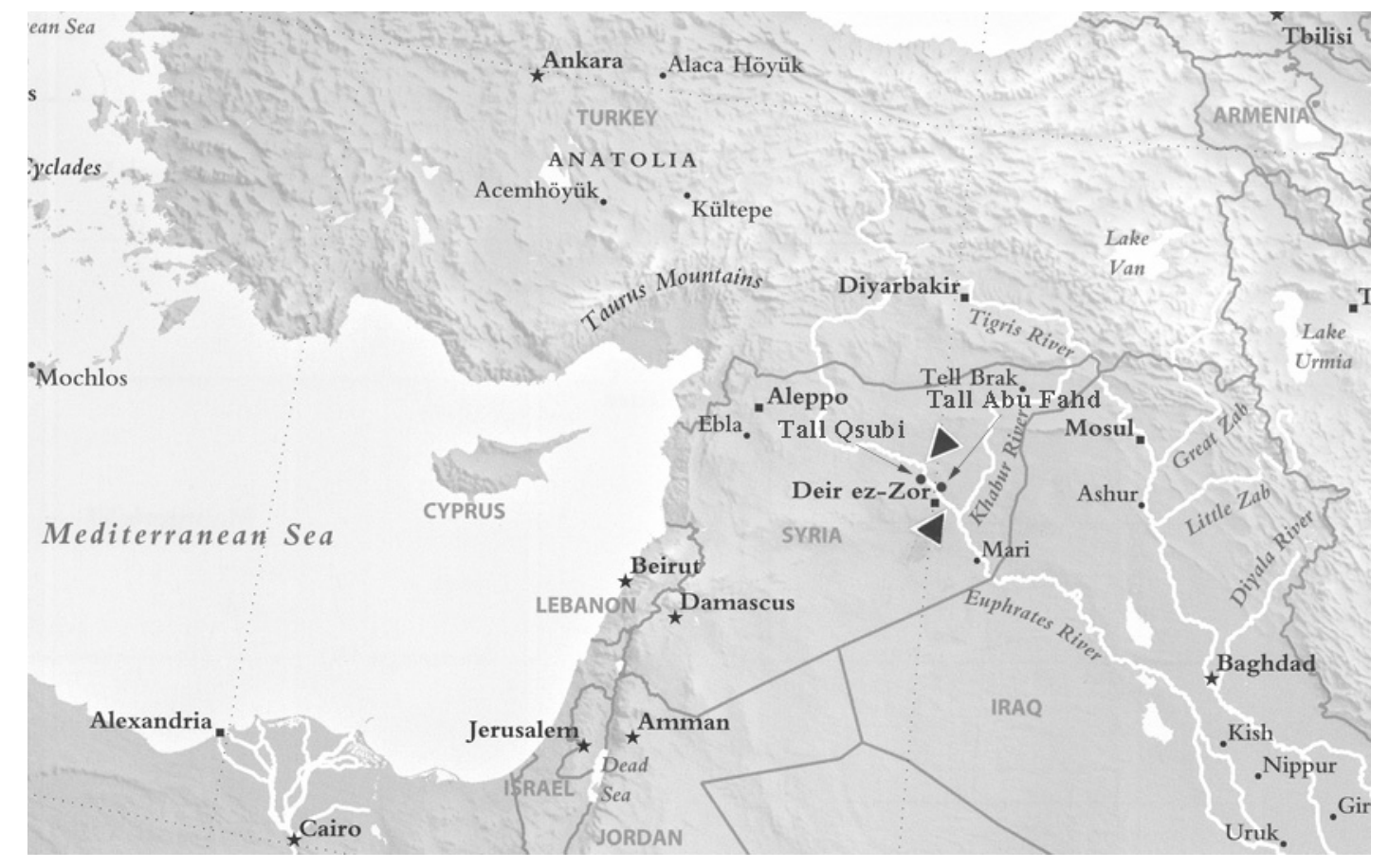

Fig. 1. Map of the studied area where the studied sites are indicated by triangles. 


\section{Sample collection}

A previous stratigraphic profile exploration was performed before sample collection. In every site two PVC cores were introduced hammering into the stratigraphic profiles at the same level (3.5 m deep in the Tall Qsubi profile and $8.5 \mathrm{~m}$ in the Tall Abu Fahd site), enabling us to obtain $30 \mathrm{~cm}$ long samples for OSL analysis. Two cores were collected from Tall Abu Fahd (TAF-1 and TAF-2) and from Tall Qsubi (TQ-1 and TQ-2). In addition, pottery fragments found on the sediments from both sites were also collected for TL measurements. Pottery samples were collected close to the sediment cores, at the same stratigraphic level. The selected samples for the luminescence study are summarised in Table 1. Moreover, from both Tall Abu Fahd cores, charcoal fragments were removed and joined to obtain a sample to date by ${ }^{14} \mathrm{C}$ (independent age).

\section{ANALYTICAL PROCEDURES}

\section{Sediment Samples}

The cores were opened in subdued red light, and then grains from the central part of the cores were reserved for luminescence analyses. To obtain quartz subsamples, the samples were dried, and sand grains within the ranges 90-180 $\mu \mathrm{m}$ and 180-250 $\mu \mathrm{m}$ were first extracted by sieving. After sieving, the samples were water-washed and treated with $10 \% \mathrm{HCl}$ and $10 \% \mathrm{H}_{2} \mathrm{O}_{2}$ to remove carbonates and organic material. $40 \% \mathrm{HF}$ was applied to remove feldspar and to etch the surface of quartz grains (to eliminate the alpha contribution). Finally, $10 \% \mathrm{HCl}$ was applied again to remove any remaining soluble fluorides and grains were dried. Quartz purification was evaluated by Mauz and Lang (2004) protocol.

For quartz subsamples blue-OSL (BL-OSL) singlealiquot regenerative dose (SAR) protocol was used for estimation of the $D_{e}$ on both $90-180 \mu \mathrm{m}$ and $180-250 \mu \mathrm{m}$ grain- sized subsamples from either TQ-2 or TAF-2. SAR measurements were performed at $125^{\circ} \mathrm{C}$ during 40 s. Preheat temperatures were chosen after performing preheat temperature tests for all samples. All aliquots showed similar $D_{e}$ 's at different preheat temperatures with differ- ent recuperation and recycling ratios. Prior to the measurements, almost all samples were preheated to $220^{\circ} \mathrm{C}$ for 10 seconds. The test-dose response was measured after heating to $160^{\circ} \mathrm{C}$.

For TQ-1 and TAF-1 no pure quartz subsamples were obtained. Thus, both feldspar contaminated quartz and not etched polymineral coarse grain subsamples (90-180 $\mu \mathrm{m}$ grain size) were tested by the double-SAR protocol (Roberts and Wintle, 2001), developed to obtain a $D_{e}$ from polymineral samples. IRSL and post-IR OSL (blue LEDs) measurements were performed at $125^{\circ} \mathrm{C}$ during 100 seconds. TAF-1 subsamples were preheated to $220^{\circ} \mathrm{C}$ for 10 seconds. Only TQ-1 feldspar contaminated quartz and polymineral subsamples were preheated to $240^{\circ} \mathrm{C}$ and $260^{\circ} \mathrm{C}$, respectively. To test the obtained $D_{e}$ 's from the double-SAR protocol (IRSL and post-IR OSL), TL measurements were performed on the feldspar contaminated quartz subsample using the total bleach method (Mejdahl, 1986) with the residual TL level defined by the TL remaining after $48 \mathrm{~h}$ bleaching to sunlight. The TL $D_{e}$ 's were calculated using the integral $300-400^{\circ} \mathrm{C}$. The glow curves were determined applying the additive dose method with linear extrapolation. The aim of this measurement is to test the reliability of the IRSL and post-IR BL-OSL measurements because of the unknown characteristics of the sediments such as partial bleaching. Thus, the post-IR OSL and IRSL $D_{e}$ 's were compared with TL $D_{e}$ using the post-IR OSL/TL and IRSL/TL ratios (Preusser, 1999) to obtain information about possible incomplete bleaching of the sediment grains.

Fading tests of Watanuki et al. (2003) were carried out on polymineral subsamples. Two consecutive doubleSAR regeneration cycles were carried out after bleaching in the OSL reader, with identical regeneration doses approximately equal to the natural dose. A regeneration dose was given for a third time. Finally, aliquots were stored at $100^{\circ} \mathrm{C}$ for two weeks and then the SAR cycle was continued, beginning with the preheating and repeated twice. Unfortunately, there was not enough material to check fading in the feldspar-contaminated subsamples.

To test for sensitivity changes, recovery tests were carried out in all subsamples. Aliquots were first bleached

Table 1. Studied samples of Syrian archaeological sites.

\begin{tabular}{lllll}
\hline Sample & Type & Measurement & Grain size $(\boldsymbol{\mu m})$ & Mineral \\
\hline TAF-2 & Sediment & OSL & $90-180$ & Quartz \\
& Sediment & OSL & $180-250$ & Quartz \\
TAF-1 & Sediment & Post-IR OSL & $90-180$ & Feldspar contaminated Quartz \\
& Sediment & IRSL & $90-180$ & Feldspar contaminated Quartz \\
& Sediment & TL (TB) & $90-180$ & Feldspar contaminated Quartz \\
& Sediment & Post-IR OSL & $90-180$ & Polymineral \\
TAF.06.P.N6.7 & Sediment & IRSL & $90-180$ & Polymineral \\
TQ-2 & Pottery & AD-TL & $90-180$ & Feldspar contaminated Quartz \\
& Sediment & OSL & $90-180$ & Quartz \\
TQ-1 & Sediment & OSL & $180-250$ & Quartz \\
& Sediment & Post-IR OSL & $90-180$ & Feldspar contaminated Quartz \\
& Sediment & IRSL & $90-180$ & Feldspar contaminated Quartz \\
& Sediment & TL (TB) & $90-180$ & Feldspar contaminated Quartz \\
& Sediment & Post-IR OSL & $90-180$ & Polymineral \\
& Sediment & IRSL & $90-180$ & Polymineral \\
\hline
\end{tabular}


in the OSL reader (200 s blue light at room temperature). A known beta dose was given approximately equal to the natural dose. Finally, quartz, feldspar contaminated quartz and polymineral aliquots were measured using the SAR and double-SAR protocols, respectively, in the usual manner.

The natural dose-rate was estimated in the laboratory using high-resolution $\gamma$-spectrometry and ICP-MS on bulk samples (results in Table 2), which were taken from the sample cores used for the $D_{e}$ determination. For the $\gamma$ spectrometry analysis, the minimum required mass quantity (200 g) could not be obtained from each core. Thus, material collected from both cores was joined to obtain enough sediment mass. This fact does not suppose a problem because samples from both sites were very close in the same stratigraphic level. Samples were sieved when the grain size was larger than $0.5 \mathrm{~mm}$ and heated at $450^{\circ} \mathrm{C}$ for 20 hours. About $150 \mathrm{~g}$ of the heated samples were then stored in a sealed flask during 30 days for radon reequilibration. High resolution gamma spectrometry analyses were carried out at the Environmental Radioactivity Laboratory of the University of A Coruna, with a Camberra XTRA gamma detector (Ge Intrinsic) during 46-68 hours counting time (Hossain et al., 2002; Poręba and Fedorowicz, 2005). For ICP-MS, $1 \mathrm{~g}$ of every sample was merged with lithium tetraborate and re-dissolved with nitric acid. For measurements an inductively coupled plasma mass spectrometer Thermo X7 was used (Aitken, 1998).

Both high-resolution $\gamma$-spectrometry and ICP-MS were used to obtain either quartz and feldsparcontaminated quartz dose-rate. Alpha contribution was not considered. For polymineral samples ICP-MS was used and alpha contribution was considered. $\gamma$-spectrometry was not used to obtain polymineral doserates because we have no data about the alpha efficiency in this kind of sediments.

\section{Pottery samples}

A $2 \mathrm{~mm}$ layer from each pottery fragment surface has been removed by sawing with a diamond-impregnated wheel. Samples were crushed by squeezing in a vice. A coarse grain quartz preparation protocol was applied. Quartz purification was evaluated by Mauz and Lang (2004) protocol and no pure quartz subsamples were obtained. The obtained feldspar contaminated quartz grains (90-180 $\mu \mathrm{m}$ grain size) were investigated by additive dose TL (Aitken, 1985). Preheat treatment of $240^{\circ} \mathrm{C}$ for 2 minutes was performed for all samples to reduce anomalous fading effects (Roque et al., 2002). Aliquots were normalized by a test dose. Also, a regeneration glow curve was performed and normalized. Sensitivity changes were not detected between first and second growth curves.

Pottery fading tests (Aitken, 1985) were carried out on the TAF.06.P.N4.2 sample before and after storage of $2 \mathrm{~min}, 4 \mathrm{~h}, 1,4$ and 15 days at $100^{\circ} \mathrm{C}$. It was found that, after laboratory irradiation and preheating at $240^{\circ} \mathrm{C}$ for 2 minutes, the measured TL signals $\left(320-420^{\circ} \mathrm{C}\right)$ tended to decrease, becoming apparently stable after 15 days of storage at $100^{\circ} \mathrm{C}$. Unfortunately, it was not possible to carry out fading test of TQ.06.P.N6.7 grains because there was not enough material.

Internal dose-rates were determined using ICP-MS. The alpha contribution was not considered and the external dose was obtained from high-resolution $\gamma$-spectrometry data from sediments.

Also, for the dating of both sediment and pottery samples, a fine grain sample preparation protocol was used with deposition of a fine grain layer on aluminium and stainless steel discs, respectively, by acetone evaporation. The fine grain subsamples were studied in order to use them to obtain measurable $D_{e} \mathrm{~s}$, but no luminescence response was found on them.

All measurements were made on an automated Ris $\varnothing$ TL/OSL-DA-15 reader equipped with an EMI 9635 QA photomultiplier tube, and using an internal ${ }^{90} \mathrm{Sr} /{ }^{90} \mathrm{Y}$

Table 2. Final ages obtained from all luminescence $D_{e}$ and dose-rate data of sediment samples.

\begin{tabular}{|c|c|c|c|c|c|c|c|c|c|c|c|}
\hline Sample & eMineral C & $\begin{array}{c}\text { Grain Size } \\
(\mu \mathrm{m})\end{array}$ & Measurement & $\begin{array}{l}\text { Num. } \\
\text { Aliquots }\end{array}$ & $\begin{array}{l}\text { ED } \\
\text { (Gy) }\end{array}$ & $\begin{array}{c}\text { ICP dose-rate } \\
\text { (Gy/ka) }\end{array}$ & $\begin{array}{c}\gamma \text {-Spectro- } \\
\text { metry dose- } \\
\text { rate } \\
(\mathrm{Gy} / \mathrm{ka})\end{array}$ & $\begin{array}{l}\text { Uncorr- } \\
\text { ected } \\
\text { ICP-MS Age } \\
\text { (ka) }\end{array}$ & $\begin{array}{l}\text { Fading } \\
\text { Ratio }\end{array}$ & $\begin{array}{l}\text { Corrected } \\
\text { ICP } \\
\text { Age } \\
\text { (ka) }\end{array}$ & $\begin{array}{c}\gamma \text {-Spectrometry } \\
\text { Age } \\
\text { (ka) }\end{array}$ \\
\hline \multirow[t]{5}{*}{ TAF-1 } & $\mathrm{FCQ}$ & $90-180$ & Post-IR OSL & 13 & $6.27 \pm 0.28$ & $2.38 \pm 0.09$ & $2.37 \pm 0.19$ & $2.64 \pm 0.15$ & - & - & $2.64 \pm 0.24$ \\
\hline & & & IRSL & 5 & $5.97 \pm 0.31$ & $2.38 \pm 0.09$ & $2.37 \pm 0.19$ & $2.51 \pm 0.18$ & - & - & $2.52 \pm 0.24$ \\
\hline & & & $\mathrm{TL}$ & 15 & $5.67 \pm 0.79$ & $2.38 \pm 0.09$ & $2.37 \pm 0.19$ & $2.38 \pm 0.35$ & - & - & $2.39 \pm 0.38$ \\
\hline & Polymin & 90-180 & Post-IR OSL & 6 & $8.05 \pm 0.30$ & $2.93 \pm 0.09$ & & $2.74 \pm 0.13$ & $0.96+0.06$ & $2.86 \pm 0.24$ & - \\
\hline & & & IRSL & 5 & $7.79 \pm 0.41$ & $2.93 \pm 0.09$ & & $2.66 \pm 0.16$ & $0.98+0.07$ & $2.71 \pm 0.26$ & - \\
\hline \multirow[t]{2}{*}{ TAF-2 } & Quartz & $90-180$ & OSL & 23 & $6.35 \pm 0.23$ & $2.38 \pm 0.09$ & $2.37 \pm 0.19$ & - & - & $2.67 \pm 0.14$ & $2.68 \pm 0.24$ \\
\hline & & $180-250$ & OSL & 16 & $6.09 \pm 0.49$ & $2.33 \pm 0.09$ & $2.32 \pm 0.19$ & - & - & $2.62 \pm 0.23$ & $2.62 \pm$ \\
\hline \multirow[t]{5}{*}{ TQ-1 } & $\mathrm{FCQ}$ & $90-180$ & Post-IR OSL & 12 & $7.26 \pm 0.24$ & $2.80 \pm 0.12$ & $2.61 \pm 0.22$ & $2.59 \pm 0.14$ & - & - & $2.78 \pm 0.16$ \\
\hline & & & IRSL & 5 & $6.10 \pm 0.47$ & $2.80 \pm 0.12$ & $2.61 \pm 0.22$ & $2.18 \pm 0.19$ & - & - & $2.34 \pm 0.21$ \\
\hline & & & $\mathrm{TL}$ & 15 & $7.99 \pm 0.70$ & $2.80 \pm 0.12$ & $2.61 \pm 0.22$ & $2.85 \pm 0.28$ & - & - & $3.07 \pm 0.31$ \\
\hline & Polymin & $90-180$ & Post-IR OSL & 3 & $8.91 \pm 0.43$ & $3.42 \pm 0.12$ & & $2.60 \pm 0.16$ & $0.92+0.05$ & $2.83 \pm 0.23$ & - \\
\hline & & & IRSL & 7 & $8.37 \pm 0.34$ & $3.42 \pm 0.12$ & & $2.44 \pm 0.14$ & $0.98+0.15$ & $2.51 \pm 0.41$ & - \\
\hline \multirow[t]{2}{*}{ TQ-2 } & Quartz & $90-180$ & OSL & 17 & $7.95 \pm 0.31$ & $2.80 \pm 0.12$ & $2.61 \pm 0.22$ & - & - & $2.84 \pm 0.17$ & $3.05 \pm 0.28$ \\
\hline & & $180-250$ & OSL & 7 & $8.60 \pm 0.58$ & $2.74 \pm 0.12$ & $2.55 \pm 0.21$ & - & - & $3.14 \pm 0.25$ & $3.37 \pm 0.36$ \\
\hline
\end{tabular}


source that provides $0.140 \pm 0.003 \mathrm{~Gy} / \mathrm{s}$. The sample grains were mounted on aluminium discs for OSL and stainless steel cups for TL measurements using silicone spray. Optically stimulated luminescence was carried out with an optical filter Hoya U-340. Filters Schott BG-39 and Corning 7-59 were employed to TL measurements.

\section{RESULTS AND DISCUSSION}

\section{Sediment Samples}

Dose-rate from ICP-MS and high-resolution $\gamma$ spectrometry data have shown similar results for each sediment sample from both sites. Results from $\gamma$ spectrometry show secular equilibrium with little $\mathrm{Pb}$ enrichment. Results from both methods have shown very close dose-rates for Tall Abu Fahd samples and good agreement for Tall Qsubi with a difference of 7\%. ICPMS obtained dose-rates show approximately half-lower standard deviation than $\gamma$-spectrometry doses.

The dose-rates of polymineral subsamples were obtained from ICP-MS data, taking into account the alpha contribution according to Adamiec and Aitken (1998) and Brennen et al. (1991). Calculated doses have shown doserates approximately $20 \%$ higher than quartz doses from both sites. We have not considered the $\gamma$-spectrometry data to calculate the polymineral dose-rates because the alpha efficiency could not be obtained and there are not previous reference data from similar sediments. Alpha contribution approximation by previous known data could not provide good dose-rate estimations. All these results are shown in Table 2.

Aliquots from all the measured sediment subsamples have shown a gaussian statistic distribution with low overdispersion. Thus, a Central Age Model was applied according to Bailey and Arnold (2006). The obtained $D_{e}$ 's from the studied quartz subsamples (90-180 and 180-250 $\mu \mathrm{m}$ grain size) are in agreement for both sites: $6.35 \pm 0.23$ Gy and $6.09 \pm 0.49$ Gy for TAF-2; $7.95 \pm 0.31$ Gy and $8.60 \pm 0.58$ Gy for TQ-2, respectively. Recycling ratios are close to 1.0 , and recuperation is lower than $10 \%$ in most of studied aliquots. Also, recovery test has shown measured/given dose ratios close to 1.0 .

The $D_{e}$ 's obtained from the feldspar contaminated quartz subsamples have shown different results for each site. In TAF-1, post-IR OSL and IRSL results are similar to the BL-OSL ones from quartz. Also, both, recycling and recuperation ratios are good for both signals. The TL measurement agrees with the OSL, which can be observed with the post-IR OSL/TL and IRSL/TL ratios (Table 3). The TL $D_{e}$ obtained from TQ-1 agrees with the $D_{e}$ from the quartz BL-OSL, but higher standard de-

Table 3. Post-IR OSL/TL and IRSL/TL ratios obtained from TAF-1 and TQ-1 feldspar contaminated quartz fraction $D_{e}$.

\begin{tabular}{lll}
\hline Sample & Measured ratio & $D_{\text {e }}$ ratios \\
\hline TAF-1 & Post-IR OSL/TL & $1.11 \pm 0.16$ \\
& IRSL/TL & $1.05 \pm 0.16$ \\
TQ-1 & Post-IR OSL/TL & $0.91 \pm 0.09$ \\
& IRSL/TL & $0.76 \pm 0.09$ \\
\hline
\end{tabular}

viation has been observed. However, the post-IR OSL $D_{e}$ is a bit lower and the IRSL $D_{e}$ is significantly lower than quartz OSL $D_{e}$ 's. This fact could not be checked by anomalous fading test because no more subsample was available.

The $D_{e}$ 's obtained from the polymineral subsamples are higher than those from feldspar contaminated quartz ones due to the alpha contribution. However, the comparison of the IRSL/post-IR OSL $D_{e}$ ratios has shown significant differences in TQ-1 subsamples. Whereas we have found ratios close to 1.0 for TAF-1 $(0.95 \pm 0.06$ in the feldspar contaminated quartz and $0.96 \pm 0.06$ in the polymineral subsample), the TQ-1 ratio is significantly lower in the feldspar contaminated quartz subsample $(0.84 \pm 0.07$ in the feldspar contaminated quartz and $0.94 \pm 0.06$ in the polymineral subsample). Thus, the OSL ages of both subsamples show low underestimation in TAF-1 and higher in TQ-1 for both signals (Fig. 2).

Calculated fading ratios allowed correcting this underestimation in the polymineral subsamples. The fading test results (Table 2) show a fading ratio of $0.96 \pm 0.06$ and $0.98 \pm 0.07$ in TAF- 1 for the post-IR OSL and IRSL, respectively, and, $0.92 \pm 0.05$ and $0.98 \pm 0.15$ in TQ- 1 for the post-IR OSL and IRSL, respectively. The corrected ages obtained from post-IR OSL and IRSL polymineral signals in TAF-1 provide luminescence ages very similar to those obtained from quartz subsamples of TAF-2. However, the polymineral IRSL corrected age of TQ-1 still shows underestimation (age ratio IRSL/post-IR OSL $0.88 \pm 0.17$ ). This fact has been previously observed in several studies. Watanuki et al. (2003) have found two likely explanations for the underestimation: insufficient fading correction, or the lifetime of luminescence signal from feldspar is too short. In this way, Wang et al. (2006) have attributed this underestimation to the too short duration of IR stimulation (100 s), compared with that from the quartz OSL signal. After sufficiently long IR exposure duration, the post-IR OSL $D_{e}$ values agree well with the quartz $D_{e}$ values. Another explanation, according to Wallinga et al. (2000), is that coarse-grain feldspar doses provided at the laboratory after preheating of the natural dose are more effective in creating luminescence. This

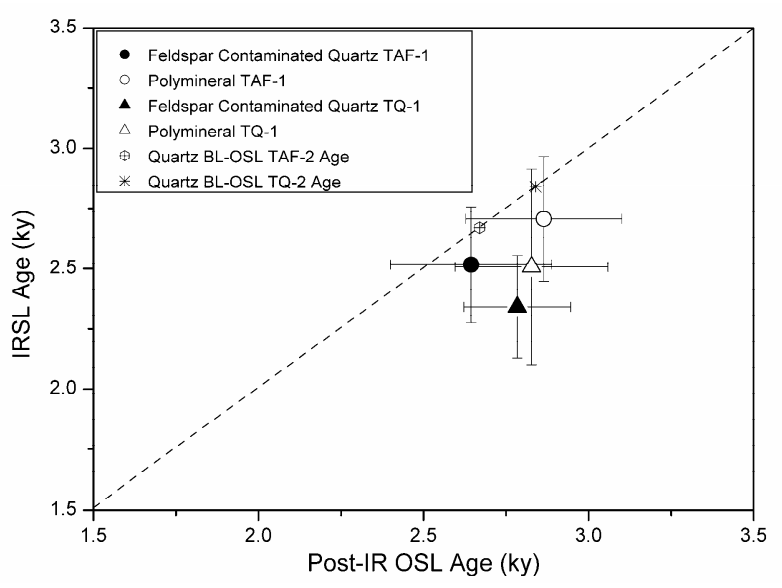

Fig. 2. Post-IR OSL/IRSL age ratios from TAF-1 and TQ-1 feldspar contaminated quartz and polymineral $D_{e} S$. 
fact very likely results in an underestimation of the natural dose when single-aliquot methods are used. Moreover, Stokes et al. (2003) noted a variable feldspar influence for many samples. They have found that its contribution may have been relatively considerably less for HF treated polymineral samples than that for not etched polymineral samples. In our case, comparison of OSL decay curves using both etched and not etched subsamples has not shown this trend in both TAF-1 and TQ-1 subsamples (Fig. 3). TQ-1 subsamples have shown higher feldspar signal influence than TAF-1 in both feldsparcontaminated quartz and polymineral subsamples.

Besides the related underestimation, a poor performance in the double-SAR protocol could be observed for the TQ-1 polymineral subsamples. Some problems were detected in the recuperation and the recycling ratios. In fact, few aliquots have shown reliable post-IR OSL doses. Preheating tests have not shown good $D_{e}$ 's from post-IR OSL signals because of the bad recuperation and recycling ratios at different preheating temperatures. However, IRSL $D_{e}$ 's have not been problematic. Banerjee et al. (2001) studied the thermal dependence of both postIR OSL and IRSL signals, and found that the post-IR OSL is more stable than the IRSL. Nevertheless, this dependence was not reflected on their preheating plateaus.
In deciding which signal provided the best $D_{e}$ estimates (Fig. 4), Roberts and Wintle (2001, 2003), Banerjee et al. (2001) and Stokes et al. (2003) chose the postIR OSL as the more appropriate signal. They assumed that post-IR OSL estimates are more likely derived primarily from the stable quartz based OSL contribution rather than feldspar. Moreover, Stokes et al. (2003) examined the exposure-decay curves of both IRSL and post-IR OSL data to obtain information of the feldspar contribution to the post-IR OSL data. The IRSL decay curves, influenced only by feldspars, exhibit generally higher relative sensitivity and slower decay form than quartz. If the IRSL signal is low, rapid post-IR OSL depletion will be observed (the post-IR OSL derived from quartz is removed in the initial few seconds of stimulation). Any signal remaining at that time is primarily derived from background contributions and feldspar. In this way, we have compared the post-IR OSL and IRSL decay curves from both feldspar contaminated quartz and polymineral subsamples of TAF-1 and TQ-1 (Fig. 3). Elevated background could be observed for the post-IR OSL from the TQ-1 polymineral subsamples. This could be related to a high feldspar contribution to the post-IR OSL signal in this sample. Also, Stokes et al. (2003) used the relationship between late $\left(10^{\text {th }} \mathrm{s}\right)$ and latest $\left(100^{\text {th }} \mathrm{s}\right)$ light to assess the degree of feldspar contribution semi-
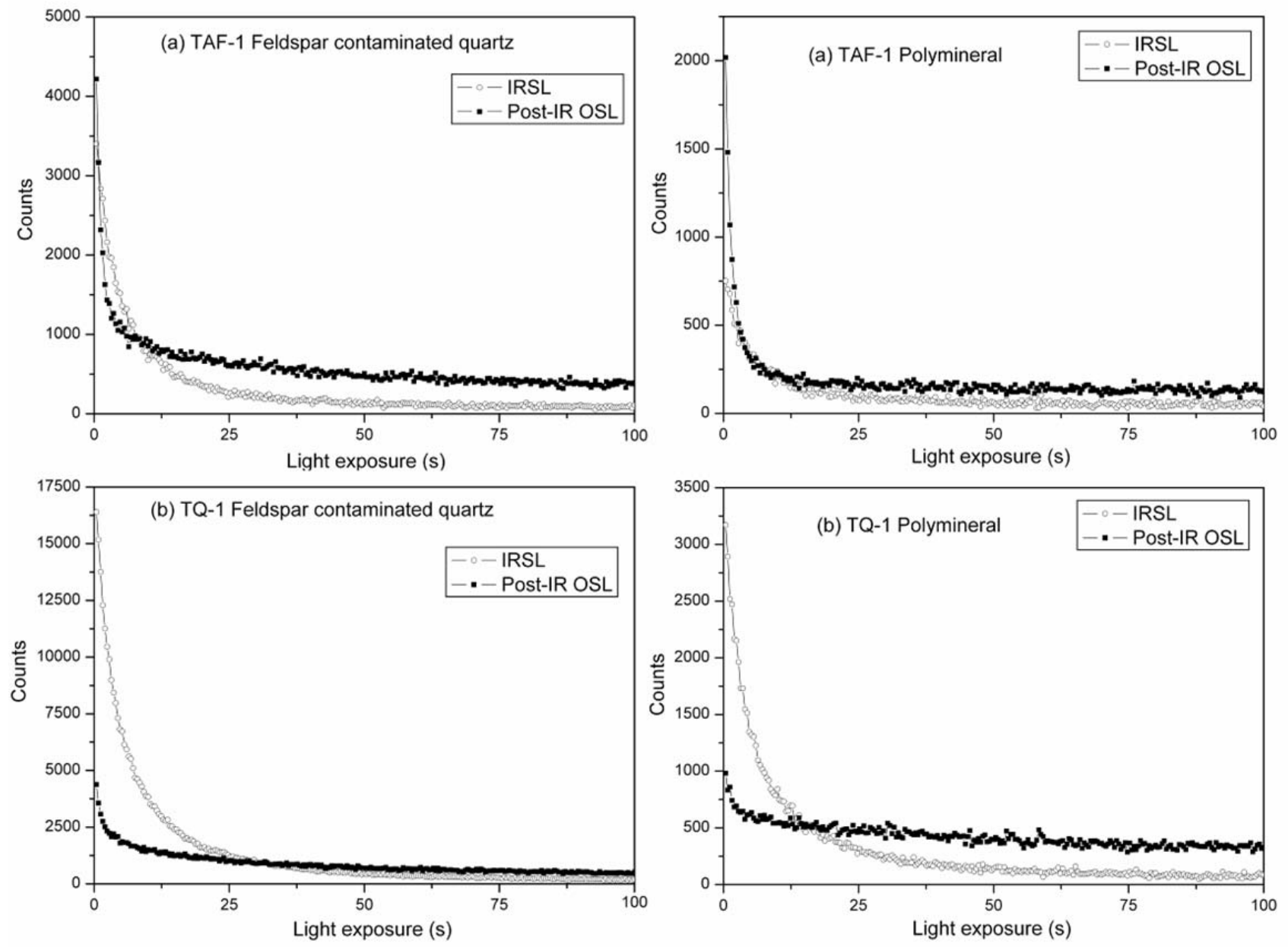

Fig. 3. Examples of decay curves of Polymineral and Feldspar contaminated quartz sub-samples Post-IR and IRSL: (a) TAF-1, (b) TQ-1. 
quantitatively. Thus, a $10 \mathrm{~s} / 100 \mathrm{~s}$ ratio of post-IR OSL > 1.2 indicates a significant feldspar contribution to the OSL signal. In our feldspar contaminated quartz and polymineral samples, we have always obtained $10 \mathrm{~s} / 100 \mathrm{~s}$ ratios of post-IR OSL over 1.2. Those are over 1.7 for TAF-1 subsamples and 1.5 for TQ-1. This fact could explain that post-IR OSL signal could show anomalous fading. Thus, it could be possible to explain the little age underestimation for TAF-1 and TQ-1 post-IR OSL measurements. In spite of this, post-IR OSL signals have provided better age estimations in both feldspar contaminated quartz and polymineral subsamples.

Also, for sediment samples, the dose recovery tests have shown measured/given dose ratios close to 1.0 in both TAF-1 and TQ-1 polymineral and feldspar contaminated quartz subsamples and in both quartz subsamples from TAF-2 and TQ-2 (Fig. 5). Poor recuperation and good recycling ratios were observed.

\section{Pottery samples}

In pottery fragments, TL measurements were also carried out from feldspar-contaminated subsamples. The few available quantity of sample TQ.06.P.N6.7 did not allow correcting the anomalous fading. Thus, an age underestimation cannot be discarded, and final TL age could be interpreted as a minimum age. Few aliquots were meas-

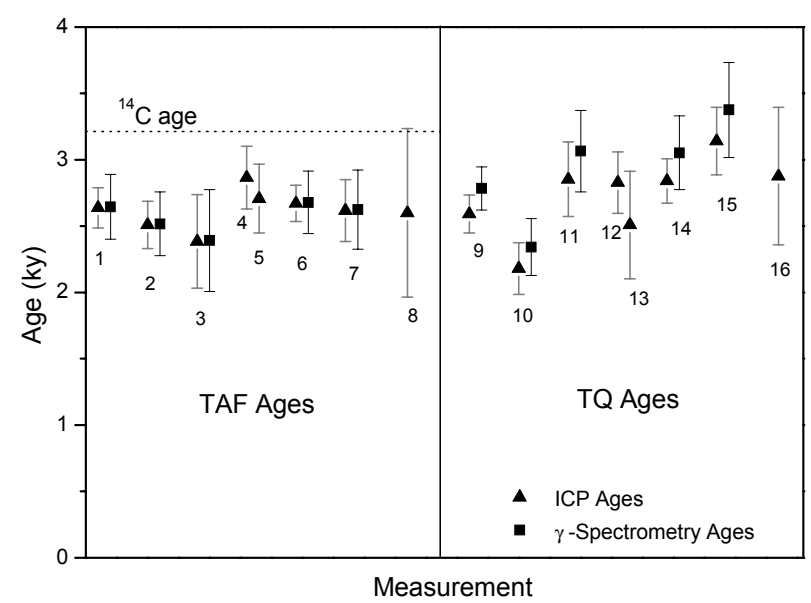

Fig. 4. Luminescence ages obtained by measurement of the studied subsamples: (1) TAF-1 Feldspar Contaminated Quartz post-IR OSL, (2) TAF-1 Feldspar Contaminated Quartz IRSL, (3) TAF-1 Feldspar Contaminated Quartz TL, (4) TAF-1 Polymineral post-IR OSL, (5) TAF1 Polymineral IRSL, (6) TAF-2 Quartz BL-OSL (grain size 90-180 $\mu \mathrm{m}$ ), (7) TAF-2 Quartz BL-OSL (grain size 180-250 $\mu \mathrm{m}$ ), (8)TAF.06.P.N4.2 Feldspar Contaminated Quartz TL, (9) TQ-1 Feldspar Contaminated Quartz post-IR OSL, (10) TQ-1 Feldspar Contaminated Quartz IRSL, (11) TQ-1 Feldspar Contaminated Quartz TL, (12) TQ-1 Polymineral post-IR OSL, (13) TQ-1 Polymineral IRSL, (14) TQ-2 Quartz BL-OSL (grain size 90-180 $\mu \mathrm{m}$ ), (15) TQ-2 Quartz BL-OSL (grain size 180-250 um), (16) TQ.06.P.N6.7 Feldspar Contaminated Quartz TL. ured (8) but a good plateau was obtained, and the final age has not very high standard deviation (16.9\%). In spite of this, the obtained final age (Table 4) is similar to quartz OSL ages obtained from TQ-2 $(\sim 3 \mathrm{ka} \mathrm{BP})$. The quantity of sample TAF.06.P.N4.2 was bigger as well as the number of measured aliquots. The measured TL showed a good test plateau and the obtained $D_{e}$ is higher than those obtained from sediments OSL (TAF-1 and TAF-2). However, the final age is a bit lower than sediments ages, and the underestimation could be due to the anomalous fading. Fading test showed a fading of $1.5 \%$, and the corrected final age is very similar to the sediment ages.

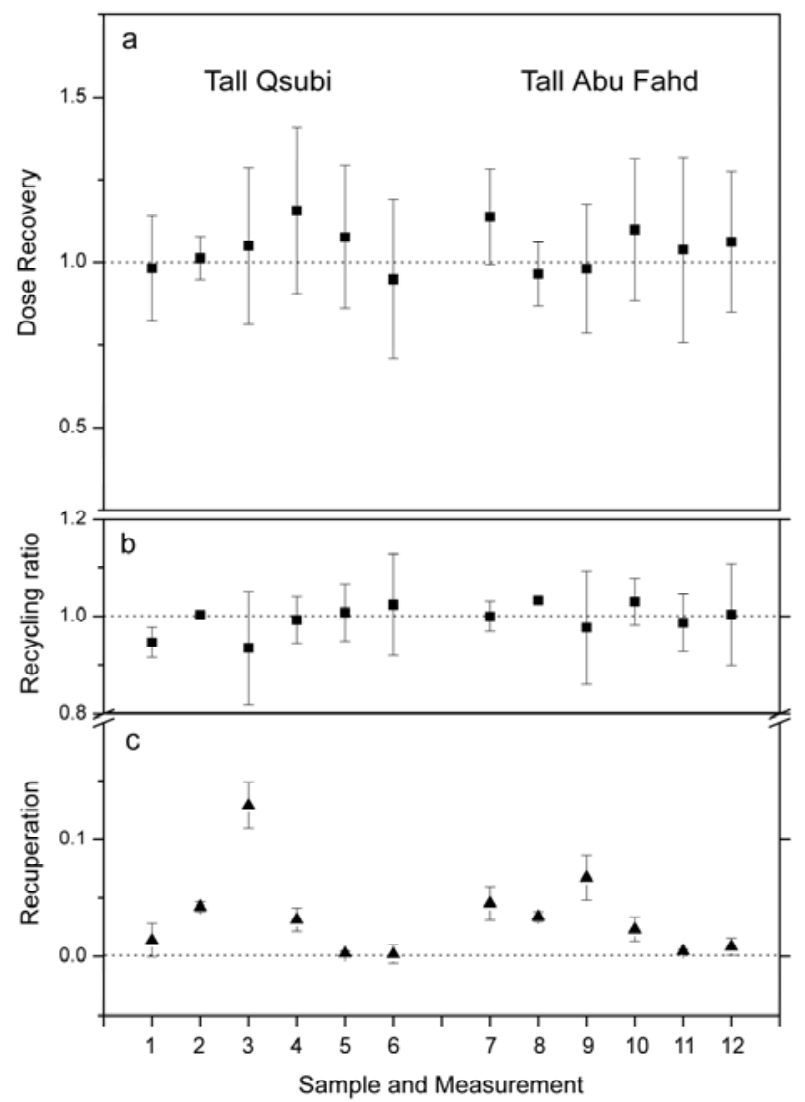

Fig. 5. Dose recovery results from all the measured subsamples. (a) Upper plot: Measured/given dose ratios; (b) Middle plot: recycling ratios; (c) Lower plot: recuperation. X-axis legend: samples and measurements: (1) Polymineral post-IR OSL from TQ-1; (2) Polymineral IRSL from TQ-1; (3) Feldspar contaminated quartz post-IR OSL from TQ-1; (4) Feldspar contaminated quartz IRSL from TQ-1; (5) Quartz (90-180 $\mu \mathrm{m}$ grain size) OSL from TQ-2; (6) Quartz (180-250 $\mu \mathrm{m}$ grain size) OSL from TQ-2; (7) Polymineral post-IR OSL from TAF-1; (8) Polymineral IRSL from TAF-1; (9) Feldspar-contaminated quartz postIR OSL from TAF-1; (10) Feldspar-contaminated quartz IRSL from TAF-1; (11) Quartz (90-180 $\mu \mathrm{m}$ grain size) OSL from TAF-2; (12) Quartz (180-250 $\mu$ m grain size) OSL from TAF-2.

Table 4. Pottery samples' final ages.

\begin{tabular}{lcccc}
\hline Sample & Num Aliquots & ED (Gy) & Dose-rate (Gy/s) & g value (\% fading/decade) \\
\hline TAF.06.P.N4.2 & 22 & $8.13 \pm 2.20$ & $4.03 \pm 0.14$ & Age (ka) \\
TQ.06.P.N6.7 & 8 & $10.43 \pm 1.77$ & $3.63 \pm 0.22$ & $2.64 \pm 0.64$ \\
\hline
\end{tabular}


The obtained luminescence ages are in agreement with the relative expected ages for both sites. Thus, Tall Qsubi samples are more ancient than Tall Abu Fahd ones. Sediment and pottery ages are also in agreement for Tall Qsubi site. An independent ${ }^{14} \mathrm{C}$ age from charcoals extracted from Tall Abu Fahd sediment samples shows an age a bit higher than OSL ages (Ua-34233, 3220 \pm 35 BP). However, the TL age of TAF.06.P.N4.2 is in agreement with ${ }^{14} \mathrm{C}$ age within error limits. This fact could indicate that the independent age corresponds to the occupation period of this site while sediment ages are more modern. Those different ages could be explained assuming that the sediment age corresponds to an event later than the occupation of the site. Thus, the dated layer of sediment could be theoretically formed after the (at least partially) destruction of the buildings, when the mineral grains were exposed to light, bleached and later buried. This event could happen decades or even centuries after the occupation period when the pottery and charcoals were originated. This fact could imply big different ages in a few centimetres of depth in the sediment, which means that the occupation period could be long.

Moreover, there is a difference between the expected archaeological ages and the absolute ages of the sites $(\sim 1 \mathrm{ka})$. The agreement of the luminescence and independent ages indicate that these are reliable data. This fact implies that the sites were inhabited and abandoned in a period later than the period supposed by archaeologists, at least at this stratigraphic level. That difference suggests that more data from upper and lower layers are necessary to obtain final archaeological conclusions. Furthermore, it could be helpful to date sediment and pottery samples from other close sites to establish more accurate absolute chronology in the studied area. If similar ages were found, it would be necessary to review the existent chronology for the Bronze Age in the area.

\section{CONCLUSIONS}

The $D_{e}$ 's obtained from the two studied quartz-grain subsamples of different size are in agreement for both sites. Ages from post-IR OSL and IRSL of feldsparcontaminated quartz measurements (TAF-1) are similar to the BL-OSL ages from quartz. In the TQ-1 sample, the $D_{e}$ obtained by TL measurements agrees well but $D_{e}$ 's by post-IR OSL and IRSL are lower. Both feldspar contaminated quartz and polymineral subsamples underestimate quartz ages. Fading tests have not corrected this underestimation for the polymineral IRSL TQ-1 signal. This fact could be attributed to an insufficient fading correction, short duration of IR stimulation compared to that from the quartz OSL signal, underestimation of the coarsegrain feldspar natural dose, or variable feldspar contribution to both post-IR OSL and IRSL signals in feldsparrich subsamples.

The high feldspar contribution to the post-IR OSL signal could explain that it shows anomalous fading. Post-IR OSL signals provide the best $D_{e}$ estimates even in samples with high feldspar contribution to the post-IR OSL signal.

The final luminescence ages obtained for both sites are in agreement with the expected relative age: ages from Tall Qsubi are higher than ages from Tall Abu Fahd. The pottery ages are consistent with sediment ages although the TQ.06.P.N6.7 could be interpreted as a minimum age. In Tall Abu Fahd (TAF) the independent ${ }^{14} \mathrm{C}$ age (Ua-34233, 3220 $\pm 35 \mathrm{BP}$ ) is higher than pottery and sediment ages. However, the wide standard deviation of the pottery age overlaps this carbon age.

\section{ACKNOWLEDGEMENTS}

This work was funded by
PGIDIT07PXIB167227PR from Xunta de
(Spain).

\section{REFERENCES}

Adamiec G and Aitken M, 1988. Dose-rate conversion factors: update. Ancient TL 16: 37-50.

Aitken MJ, 1985. Thermoluminescence dating. London, Academic Press: 279pp.

Bailey RM and Arnold LJ, 2006. Statistical modelling of single grain quartz $\mathrm{D}_{\mathrm{e}}$ distributions and an assessment of procedures for estimating burial dose. Quaternary Science Reviews 25(19-20): 24752502, DOI 10.1016/j.quascirev.2005.09.012.

Banerjee D, Murray AS, Botter-Jensen L and Lang A, 2001. Equivalent dose estimation using a single aliquot of polymineral fine grains. Radiation Measurements 33(1): 73-94, DOI 10.1016/S13504487(00)00101-3.

Brennen BJ, Lyons RG and Phillips SW, 1991. Attenuation of alpha particle track dose for spherical grains. Nuclear Tracks and Radiation Measurements 18(1-2): 249-253, DOI 10.1016/13590189(91)90119-3.

Grogler N, Houtermans FG and Stauffer H, 1958. Radiation damage as a research tools for geology and prehistory. Convengo sulle dotazioni con metodi nuclear. $5^{\text {th }}$ Internazation Elettr Nucl Sezione Nuclear Roma: 5-15.

Hossain SM, De Corte F, Vandenberghe D and Van den haute P, 2002. A comparison of methods for the annual radiation dose determination in the luminescence dating of loess sediment. Nuclear Instruments and Methods in Physics Research A 490(3): 598-613, DOI 10.1016/S0168-9002(02)01078-1.

Lauffray J, 1983. Halabiyya-Zenobia, place forte du limes oriental et la Haute-Mésopotamie au VIe siècle (Halabiyya-Zenobia, eastern lime stronghold of and Ninurta at 6th Century). Paris, Geuthner Ed: 295pp.

Mauz B and Lang A, 2004. Removal of the feldspar-derived luminescence component from polymineral fine silt samples for optical dating applications: evaluation of chemical treatment protocols and quality control procedures. Ancient TL 22(1): 1-8.

Mejdahl V, 1986. Thermoluminescence dating of sediments. Radiation Protection Dosimetry 17: 219-227.

Montero Fenollós JL, Caramelo F, Márquez I and Vidal J, 2006a. O projecto arqueológico Médio Euferates Sírio: resultado provisórios da primeira campanha (The archaeological project Syrian Middle Euphrates: second campaign prospecting in the region of Halabiye / Hanouqa (Deir Futowa, Syria)). Revista Portuguesa de Arqueología 9: 109-126 (in Portuguese with English abstract).

Montero Fenollós JL, Caramelo F, Márquez I and Vidal J, 2006b. Le projet archéologique Moyen Euphrate Syrie: 2e campagne de prospection dans la région de Halabiyé/Hanouqa (Deir ez-Zor, Syrie) (The archaeological project Syrian Middle Euphrates: second campaign prospecting in the region of Halabiye / Hanouqa -Deir Futowa, Syria). Orient-Express 2006/4: 99-102 (in French).

Murray AS and Wintle AG, 2000. Luminescence dating of quartz using an improved single-aliquot regenerative-dose protocol. Radiation Measurements 32(1): 57-73, DOI 10.1016/S1350-4487(99)00253$\mathrm{X}$.

Poręba GJ and Fedorowicz S, 2005. Gamma spectrometry for OSL and TL dating of loess deposits at Dybawka and Tarnawce (SE Poland). Geochronometria 24: 27-32.

Preusser F, 1999. Luminescence dating of fluvial sediments and overbank deposits from Gossau, Switzerland: fine grain dating. Qua- 
ternary Science Reviews 18(2): 217-222, DOI 10.1016/S02773791(98)00054-7.

Roberts HM and Wintle A, 2001. Equivalent dose determinations for polymineralic fine-grains using the SAR protocol: application to a Holocene sequence of Chinese Loess Plateau. Quaternary Science Reviews 20(5-9): 859-863, DOI 10.1016/S0277-3791(00)00051-2.

Roberts HM and Wintle AG, 2003. Luminescence sensitivity changes of polymineral fine grains during IRSL and (post-IR) OSL measurements. Radiation Measurements 37(6): 661-671, DOI 10.1016/S1350-4487(03)00245-2.

Roque C, Guibert E, Vartanian E and Bechtel F, 2002. The chronology of the neolithic sequence at Dikili Tash, Macedonia, Greece: TL dating of domestic ovens. Archaeometry 44(4): 613-633, DOI 10.1111/1475-4754.00089.

Stokes S, Hetzel R, Bailey RM and Mingxin T, 2003. Combined IRSL-
OSL single aliquot regeneration (SAR) equivalent dose $\left(D_{e}\right)$ estimates from source proximal Chinese loess. Quaternary Science Reviews 22(10-13): 975-983, DOI 10.1016/S0277-3791(03)000441.

Wallinga J, Murray A and Duller G, 2000. Underestimation of equivalent dose single-aliquot optical dating of feldspars caused by preheating. Radiation Measurements 32(5-6): 691-695, DOI 10.1016/S1350-4487(00)00127-X.

Wang X, Lu Y and Zhao H, 2006. On the performances of the singlealiquot regenerative-dose (SAR) protocol for Chinese loess: fine grain quartz and polymineral grains. Radiation Measurements 41(1): 1-8, DOI 10.1016/j.radmeas.2005.02.010.

Watanuki T, Murray AS and Tsukamoto S, 2003. A comparison of OSL ages derived from silt-sized quartz and polymineral grains from Chinese loess. Quaternary Science Reviews 22(10-13): 991-997, DOI 10.1016/S0277-3791(03)00053-2. 